\section{BIOLOGÍA SINTÉTICA: LA INGENIERÍA AL ASALTO DE LA COMPLEJIDAD BIOLÓGICA}

\author{
Víctor de Lorenzo \\ Centro Nacional de Biotecnología \\ Consejo Superior de Investigaciones Científicas \\ vdlorenzo@cnb.csic.es
}

Cómo citar este artículo/Citation: Lorenzo, V. de (2014). "Biología sintética: la ingeniería al asalto de la complejidad biológica". Arbor, 190 (768): a149. doi: http://dx.doi. org/10.3989/arbor.2014.768n4003

Recibido: 9 junio 2014. Aceptado: 14 julio 2014.

RESUMEN: La Biología sintética no es solo una reformulación contemporánea de las tecnologías del ADN recombinante de los últimos 30 años junto con un lenguaje descriptivo importado de la ingeniería eléctrica e industrial. Es también una nueva clave interpretativa de los sistemas vivos y una declaración de intenciones sobre la utilización y reprogramación de los objetos biológicos en beneficio humano. De la misma forma que la Química científica iniciada por Lavoisier devino en la Ingeniería química que está en la base de nuestra sociedad desarrollada, la Biología ha adquirido un potencial transformador que posiblemente nos lleve a un tipo de industria y de economía muy distinta de la actual. Para ello es esencial identificar los cuellos de botella que limitan el diseño de objetos biológicos desde sus primeros principios y no perder el tren de la Biología sintética en su etapa fundacional, cuando el talento -y no el músculo- es lo determinante.

PALABRAS CLAVE: Ingeniería genética; circuitos; sistemas mínimos; partes; dispositivos; módulos; sistemas; chasis; microorganismos; biocombustibles.

\section{SYNTHETIC BIOLOGY: ENGINEERING FOR CONQUERING BIOLOGICAL COMPLEXITY}

Copyright: (C) 2014 CSIC. Este es un artículo de acceso abierto distribuido bajo los términos de la licencia Creative Commons Attribution-Non Commercial (by-nc) Spain 3.0.

ABSTRACT: Synthetic Biology is not just a contemporary update of the recombinant DNA technologies of the past 30 years along with a descriptive language imported from electrical and industrial engineering. It is also a new key to interpreting living systems, as well as a declaration of intent about the use and reprogramming of biological objects for human benefit. In the same way that scientific chemistry initiated by Lavoisier evolved into the Chemical Engineering that is the basis of our industrial society, Biology has acquired a transforming potential that will possibly lead to a type of industry and economy very different from the current paradigm. To this end, it is essential to identify bottlenecks that limit the design of biological objects from first principles and not to miss the train of Synthetic Biology at its current foundational stage, when talent -and not muscle- is what really matters.

KEYWORDS: Genetic engineering; circuits; minimal systems; parts; devices; modules; systems; chassis; microorganisms; biofuels. 


\section{INTRODUCCIÓN}

Desde el comienzo del milenio la Biología está experimentando una transición acelerada entre ser una ciencia predominantemente descriptiva a ser una disciplina cuantitativa. Este proceso comenzó con el famoso opúsculo de E. Schrödinger ¿Qué es la vida? escrito al final de la Segunda Guerra Mundial (Schrödinger, 1944) en el que por primera vez se planteó rigurosamente el abordaje de los sistemas biológicos como entidades sujetas a las mismas reglas de la Física que el resto del mundo material. El punto álgido de esta nueva visión fue el desciframiento hace 50 años y en el periodo inmediatamente posterior de la estructura del ADN, del código genético y de los elementos que participan en el flujo de información del ADN a las proteínas. Pero, paradójicamente, el protagonismo de los físicos en el nacimiento de la Biología molecular no se tradujo en una cultura cuantitativa y un lenguaje descriptivo preciso y estandarizado que es característico de las ciencias "duras". Muy al contrario, la Genética molecular y la Biología que surgió de ella no aprovechó (salvo muy contadas excepciones) la oportunidad de formalizar los mecanismos y las funciones presentes en los sistemas vivos con enunciados y códigos precisos. El resultado ha sido décadas de completo desbarajuste en la nomenclatura de los genes y en las formas de medir y cuantificar las actividades biológicas, por no decir la explosión de todo tipo de vectores de ADN para la manipulación genética de los sistemas experimentales bajo estudio. Quizá el gamberrismo científico glorificado en La doble hélice de J. Watson (Watson, 1968) no ha sido ajeno al ethos informal y anti-autoritario de la comunidad científica nacida a partir de ese periodo. Mientras que esto no ha sido problema durante mucho tiempo, lo cierto es que tanto los avances propios en este ámbito como el papel creciente de la Biología y la Biotecnología en campos más allá del entorno académico vuelven a plantear con fuerza la necesidad de dotar a las Ciencias de la Vida de metodologías y lenguajes más cercanos a la Física que a las ciencias narrativas -tal y como ha sido la Biología la mayor parte de su historia. Es en este contexto donde aparecen los dos últimos intentos de cuantificar la Biología que están llamados a cambiar por entero -tanto metodológicamente como conceptualmente- nuestros abordajes a las preguntas científicas y a sus derivadas biotecnológicas.

\section{DE LA BIOLOGÍA MOLECULAR A LA Biología dE SISTEMAS Y A LA BIOLOGÍA SINTÉTICA}

El comienzo de la Biología de sistemas estuvo determinado por un problema muy práctico: cómo organizar y como buscarle sentido a la avalancha de datos deri- vados de las tecnologías generalmente conocidas como ómicas que se empezaron a aplicar a los sistemas biológicos desde finales de los años 90. A la secuenciación de genomas completos siguieron luego los transcriptomas, los proteomas y los metabolomas. Por elevación, estos derivaron a sus correspondientes versiones meta (es decir, datos de poblaciones multi-especies), así como el sondeo de los mismos datos en células individuales. Desafortunadamente, los datos per se no se convierten automáticamente en información y mucho menos en conocimiento. Para ello es necesario procesarlos con tecnologías que no vienen en absoluto de la Biología, sino de la computación, la informática y de la física de sistemas complejos. De hecho, las técnicas ómicas permiten disponer de todos los datos contenidos en un sistema biológico pero en una forma más o menos críptica que necesita ser descifrada para su comprensión pero con instrumentos ajenos a la Biología (por ejemplo la teoría de redes, cf. Barabasi y Oltvai, 2004). Esto implica al tiempo una oportunidad (entender un sistema vivo por completo más que sus partes por separado) y un gran reto metodológico y epistemológico. Por un lado, el análisis de los datos masivos se convierte no solo en una ayuda a la experimentación, sino en una genuina fuente de nueva información y conocimiento. Esta forma de investigar es ajena a la gran tradición hipotéticadeductiva de la Biología experimental pero muy posiblemente igual de válida. Ramas enteras de la Biología que hace veinticinco años eran fundamentalmente experimentales (por ejemplo, la Ecología microbiana) se están convirtiendo en grandes plataformas de análisis de secuencias. Por otro lado, los datos deben siempre proyectarse sobre algún modelo de funcionamiento, lo que ha empujado una buena parte de los Biólogos sistémicos a especializarse en la representación de datos y en la modelización de su funcionamiento, a menudo importando formalismos para el estudio de redes y la construcción de circuitos electrónicos. Esto a su vez genera nuevas preguntas y nuevas agendas investigadoras en las que el objetivo es comprender la complejidad multi-escala de los objetos vivos. Por primera vez se plantea la posibilidad de entender la arquitectura material (el hardware) y la lógica operativa (el software) de un sistema vivo (Danchin, 2009a). Y para entender el todo hay estudiar el todo como tal, no solo centrarse en los detalles de sus componentes. Con este fin hay que echar mano de abstracciones y simplificaciones típicas de la Física que ayuden a separar los componentes principales de un sistema de los que solamente son espectadores o transeúntes.

Esto lleva a la siguiente etapa: la definición de los componentes mínimos que debe tener un sistema 
biológico para mantener su identidad y sus funciones. $Y$ al final, la comprensión total de un sistema requiere no solo su análisis, sino también su síntesis, tal y como proclamaba en su célebre pizarra póstuma el Premio Nobel de Física Richard Feynman “... Lo que no puedo crear, no lo entiendo..." Es por tanto la Biología de sistemas y su énfasis en la cuantificación, la modelización y el uso combinado del análisis y la síntesis para entender a las entidades vivas quien puso el escenario a principio del milenio para el nacimiento y el desarrollo explosivo de la Biología sintética tal y como estamos presenciando en el tiempo que nos toca vivir.

\section{MIRAR LOS SISTEMAS VIVOS CON OJOS DE INGENIERO}

La cuantificación de la Biología y las abstracciones que son la marca de identidad de la Biología de sistemas hacen casi inevitable un nuevo marco interpretativo de los objetos vivos. La Biología del siglo XX ha utilizado para la comprensión de los sistemas biológicos dos claves hermenéuticas relacionadas. La primera y principal es la teoría evolutiva. Tal y como proclama la conocida aseveración de Dobzhansky “... En Biología nada tiene sentido, si no es a la luz de la evolución...". Esto define la razón de ser de los objetos biológicos como resultado de un proceso temporal no-dirigido de complejidad y de interactividad en beneficio de la adaptación ambiental y el éxito reproductivo. La otra clave es lo que se ha venido a llamar el Dogma Central (DC) de la Biología molecular, es decir el flujo de información DNA $\rightarrow$ RNA $\rightarrow$ Proteínas. Estas dos claves (la evolución y el DC) permiten contestar a la pregunta de porqué los sistemas biológicos son como son tal y como los conocemos. Pero en realidad, las mismas claves no nos dicen gran cosa sobre el funcionamiento del mismo sistema natural, y mucho menos sobre si este podría ser distinto, mecanísticamente, a lo que vemos aquí y ahora.

La evolución selecciona funciones y sus constelaciones, pero no necesariamente los mecanismos específicos que proporcionan esa funcionalidad. Esto se puede ver claramente en el mundo procariótico: un mismo problema metabólico o regulador puede solucionarse a través de esquemas moleculares distintos (Cases y de Lorenzo, 2001). La pregunta sobre cómo funciona un sistema biológico es por tanto difícil de contestar con una mera óptica evolutiva. Y aquí viene la propuesta revolucionaria de la Biología sintética: para entender el funcionamiento de los sistemas vivos tenemos que contemplarlos como si fueran objetos no distintos a los que diseña un ingeniero computacional, químico o electrónico (Endy, 2005). Por ejemplo, para enten- der la distribución espacio-temporal del metabolismo en una bacteria no nos ayuda gran cosa el conocer su origen evolutivo. Por el contrario nos tendríamos que preguntar lo que se preguntaría un ingeniero químico para diseñar un micro-reactor en el que miles de reacciones ocurren simultáneamente en el espacio y en el tiempo. De esta pregunta se deriva, por ejemplo, la necesidad de compartimentalización (o al menos limitaciones a la difusión libre), la existencia de canalización de substratos y productos, el envejecimiento de las proteínas, el problema de los residuos tóxicos, etc. (de Lorenzo y Danchin, 2008). Solo con esa perspectiva ingenieril podemos comprender ese sistema físicoquímico que es la célula en el espacio y en el tiempo -dejando aparte la pregunta sobre sus orígenes.

En general, los objetos procedentes de la ingeniería deben cumplir una función para la que necesitan unas instrucciones (el software en los ordenadores) que se implementan a través de un hardware (la maquina que lee y ejecuta las instrucciones). La Biología molecular tradicional tiende a olvidar la distinción entre función, instrucciones (software y sistema operativo) y la maquinaria para ejecutarlas (hardware), lo que reclama una cierta cualificación de la frase de Dobzhansky mencionada antes: la evolución selecciona predominantemente las funciones y sus combinaciones, pero no tanto las instrucciones ni las formas de leerlas. Lo que sí es característico de los sistemas vivos es que buena parte de su software/hardware está dedicado a su auto-replicación. En este sentido, tal y como ha propuesto el científico francés A. Danchin, las células pueden asemejarse a máquinas de Turing capaz de interpretar símbolos (por ejemplo químicos: ATGC) impresos en una cinta (el DNA/RNA en nuestro caso) de acuerdo a una tabla de reglas de la misma forma que lo hacen los ordenadores (Danchin, 2009b). Una máquina de este tipo puede ser adaptada para ejecutar todo tipo de operaciones, incluyendo instrucciones sobre su propio ensamblaje. Llevando esta metáfora al extremo, las células pueden entenderse como ordenadores que hacen ordenadores (Danchin, 2009a).

\section{TECNO-LOGÍA VS TECNO-NOMÍA}

Pero el enunciado Biología-como-ingeniería precisa varias matizaciones. Primero, el mirar a los objetos biológicos como si fueran el producto de una ingeniería no dice nada sobre la intervención de un ingeniero. Un argumento similar fue utilizado por J. Monod en su celebrada discusión sobre la teleología (finalidad de los sistemas biológicos) y la teleonomía (apariencia de finalidad en los mismos sistemas) de 
su libro El azar y la necesidad (Monod, 1970). Mientras que la primera no está acreditada como un hecho científico, la segunda es una clave interpretativa extremadamente útil para entender porqué los sistemas biológicos son como son en vez de ser diferentes. Por la misma razón se puede adaptar la ingeniería como una metáfora y una clave hermenéutica para comprender la lógica de los objetos biológicos, que es distinta, pero perfectamente compatible con otras claves que abordan preguntas diferentes. En este sentido, a la tensión teleología (finalidad) vs. teleonomía (apariencia de finalidad) le correspondería un co-relato tecno-logía (diseño) / tecno-nomía (apariencia de diseño).

Pero aparte de estos argumentos un tanto especulativos, ¿podemos realmente considerar a los sistemas vivos con la perspectiva de un ingeniero? En su día, F. Jacob propuso un contraste insuperable entre la ingeniería y el bricolaje (en inglés: tinkering) como metáfora de lo distinto que es el diseño racional de la evolución biológica (Jacob, 1977). Mientras que el trabajo de los ingenieros se apoya en componentes precisos y herramientas que se ajustan exactamente a un proyecto predefinido, el aficionado al bricolaje juega con trastos y sobras sin saber lo que va a producir y utiliza todo lo que encuentra a su alrededor para hacer algún tipo de objeto funcional, cuya utilidad quizá se manifiesta después: ninguno de los materiales tiene en origen una función precisa y cada uno se puede utilizar de varias maneras diferentes. Sin embargo, esta visión parece transmitir que la estructura de los sistemas vivos no tiene ninguna lógica relacional comparable a la ingeniería. Nada más lejos de la realidad. Aunque las soluciones a problemas de diseño aparezcan por caminos distintos, las dos frecuentemente coinciden o convergen y una puede fácilmente ayudar a comprender la otra.

Lo mismo puede aplicarse a los sistemas biológicos: aunque su estructura y funcionamiento no pueden atribuirse a un ingeniero, es muy útil examinarlas con la perspectiva y los formalismos que proporciona la ingeniería. Funciones y módulos biológicos que constituyeron una innovación evolutiva para solucionar un problema frecuentemente se asimilan en otro contexto para arreglar un reto diferente. Por ejemplo, el plumaje apareció en su momento como un mero aislamiento térmico pero luego se transformó en un componente esencial del vuelo de los pájaros. El análisis de los genomas bacterianos proporciona incontables ejemplos de proteínas que nacen para hacer algo que luego resulta ser muy distinto de aquello para lo que finalmente se utilizan (Milanesio et al., 2011). Este proceso, que en Biología evolutiva se denomina exaptación, tiene también incontables equivalentes en ingeniería: un dispositivo que se inventa con un propósito muy específico reaparece con pequeñas modificaciones en otro sitio con una finalidad inesperada e incluso opuesta a la inicial. Este escenario aparece constantemente en los sistemas biológicos y en los sistemas diseñados, lo que disminuye la brecha insalvable entre los dos tal y como lo planteó Jacob. Sin embargo, el principio de tecno-nomía que se propone en este artículo será difícil de debatir serenamente en un momento de confrontación entre el evolucionismo y el diseño inteligente, que ha adquirido gran virulencia en los países anglosajones y ha reverberado en todos los demás. En cualquier caso y de forma más o menos explícita, el mirar a los objetos biológicos con ojos de ingeniero es y será el mayor y más útil pilar conceptual de la Biología sintética.

\section{La modularidad de los sistemas biológicos}

Una segunda matización sobre la relación BiologíaIngeniería tiene que ver con la estructura modular de los objetos de estudio en cada caso. Cualquier entidad diseñada por un ingeniero está compuesta de módulos claramente definidos, con conectividades entre sus componentes bien estandarizadas (lo que permite su re-uso en contextos diferentes), con entradas y salidas compatibles y con una clara jerarquía y disposición en tres dimensiones de los distintos componentes. Esto hace que la modularidad física de los objetos hechos por los ingenieros coincida, al menos aproximadamente, con la funcional. Por el contrario, los sistemas biológicos existentes no parecen a primera vista manifestar esta coincidencia entre lo físico y lo funcional. El catálogo de funciones necesarias para tener un sistema vivo se ha podido cuantificar en unas $300-500$ a base de comparar los grupos de genes persistentes en los genomas microbianos (de Lorenzo y Danchin, 2008). Sin embargo, al buscar genes específicos compartidos entre esos mismos genomas, la sorprendente conclusión es que ese número es exactamente cero (Acevedo-Rocha et al., 2013). Eso significa que las mismas necesidades funcionales pueden ser cubiertas por configuraciones muy distintas de genes y moléculas.

Otro detalle notable que separa los objetos diseñados y los sistemas biológicos son las características físicas de sus componentes: los teléfonos y 
los aviones están hechos con materiales duros, con componentes perfectamente definidos en su estructura tridimensional y con conexiones precisas con los componentes vecinos. La aparición de interacciones no previstas suele dar problemas y causar accidentes. Por el contrario, los objetos biológicos están compuestos típicamente de elementos blandos, a veces sin límites bien claros y con tendencia a interaccionar los unos con los otros -lo que a veces lleva a la aparición de propiedades emergentes no anticipadas. Si la ingeniería eléctrica e industrial va de cables, tubos y tornillos, los sistemas vivos están compuestos de elastómeros, gelatinas y pegamentos. Finalmente, los sistemas vivos crecen, replican y se reproducen -propiedades ajenas a los objetos hechos por ingeniería racional que conocemos ¿Significa esto que el principio de modularidad que asociamos a los dispositivos hechos por el hombre está ausente de los sistemas biológicos? De nuevo la respuesta es no. La complejidad de las células con grandes genomas y extensa diversidad bioquímica es engañosa a este respecto. El análisis de los genomas mínimos encontrados, por ejemplo, en las bacterias endosimbiontes revela un considerable grado de modularidad en las funciones esenciales que permiten su existencia (Porcar et al., 2013). La sopa bioquímica que a veces parece ser el metabolismo está perfectamente modularizada, con una organización que recuerda una factoría química. En la dirección contraria, la idea de objetos autoreplicativos tampoco es nueva en ingeniería, tal y como lo demuestran los intentos en la última década de diseñar impresoras tridimensionales que se impriman a ellas mismas (por ejemplo, el proyecto RepRap: http://reprap.org/).

Es por tanto tan posible y productivo usar la metáfora e incluso los formalismos de la ingeniería para comprender el funcionamiento de los sistemas biológicos como la metáfora biológica para guiar el diseño de nuevos dispositivos hechos por el hombre. En este sentido, una buena parte de la ingeniería contemporánea está habituada a explorar aleatoriamente el espacio de soluciones a un problema cuya solución no de puede abordar desde primeros principios. Para ello se adoptan estrategias de intentos y errores que no son muy distintos de los procesos evolutivos en Biología. El propio Gaudí, en un momento histórico sin capacidad computacional ni las simulaciones que son hoy tan habituales en la arquitectura moderna, fue capaz de calcular parámetros complejos en sus edificios a base de interrogar a la naturaleza (en su caso, por pura gravedad en mode- los de cuerdas y pesos) sobre la configuración óptima de los componentes de sus grandes obras. Lo interesante en este caso es que tales soluciones son virtualmente idénticas a las encontradas por los arquitectos muchos años más tarde usando computaciones y simulaciones avanzadas (Huerta, 2006). Parece por tanto que en la ingeniería como en la Biología, el espacio de soluciones a un reto adaptativo tiene atractores en los que el mismo desenlace puede ser el resultado de un diseño dirigido o una exploración aleatoria. A efectos prácticos, esto acredita el valor y la utilidad de examinar la lógica composicional de los sistemas vivos con las herramientas conceptuales de la ingeniería.

\section{La ingeniería genética: analogía y metodología}

La opción por la ingeniería como clave para interpretar fenómenos biológicos que hace la Biología sintética tiene una derivada al tiempo fascinante e inquietante. No es solo una cuestión epistemológica, sino también muy práctica. Si un sistema biológico es como un artefacto hecho por ingeniería, entonces también podemos despiezarlo en un conjunto limitado de componentes definidos que luego podemos recomponer para generar un objeto distinto siguiendo un plan racional. El resultado puede ser un objeto con una estructura y unas propiedades distintas a las que tenía la fuente original de esos mismos componentes. Pero para hacerlo necesitamos dos cosas. En primer lugar, la abstracción relacional y jerárquica del nuevo objeto como un conjunto de partes (las unidades básicas de función biológica) que se conectan de forma racional para formar dispositivos y estos a su vez para generar sistemas de complejidad creciente. En este punto saltamos de la ingeniería como metáfora y analogía (como en la ingeniería genética) a la ingeniería como auténtica metodología para construir objetos biológicos. En este sentido, la formulación narrativa de la Biología molecular como un proceso ADN $\rightarrow$ ARN $\rightarrow$ proteínas se sustituye por el principio composicional y cuantitativo de la Biología sintética: Partes $\rightarrow$ dispositivos $\rightarrow$ sistemas (Figura 1 ).

En segundo lugar, las partes para la ingeniería de nuevos sistemas biológicos necesitan estar estandarizadas para hacerlas reusables, composicionables y escalables. En la mayoría de los casos, estas partes no aparecen así en su situación natural. Podemos hacer una choza con los troncos de un árbol tal y como los da la Naturaleza. Pero para hacer una casa los troncos deben convertirse en vigas y paneles de dimensiones precisas que permitan la construcción 
Figura 1. La Biología molecular y la Biología sintética abordan los sistemas vivos con diferentes claves interpretativas

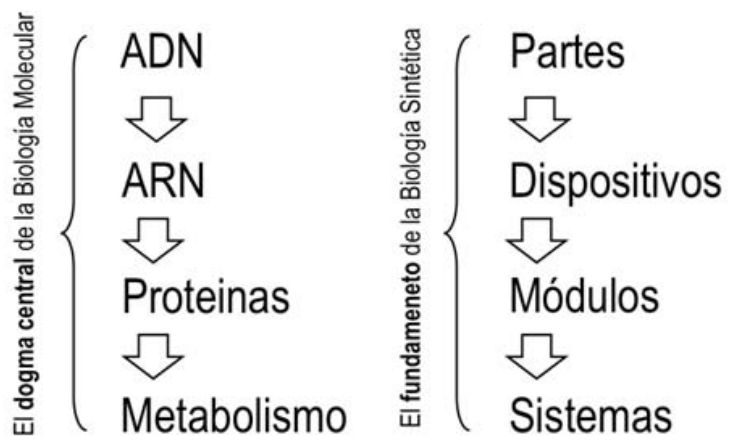

El dogma central de la Biología molecular (izquierda) se centra en la transferencia de información de residuo a los residuo del ADN a las proteínas y (como se ha propuesto recientemente: de Lorenzo, 2014) el despliegue de ese flujo de información sobre el funcionamiento de las redes metabólicas. Por el contrario, la Biología sintética (derecha) pone el énfasis en la lógica relacional y composicional de los sistemas vivos, tanto los existentes como los que se puedan diseñar en el futuro.

de un edificio más complejo. Mediante este razonamiento, una de las señas de identidad de la Biología sintética es el esfuerzo por partir de secuencias de ADN que determinan funciones deseables y modificarlas para que puedan utilizarse como bloques de construcción (bio-ladrillos) de nuevos objetos biológicos (Kosuri et al., 2013; Mutalik et al., 2013). Partiendo de la situación existente, uno puede pensar en modularizar más y más las funciones y los componentes biológicos para hacerlos más fáciles de combinar, tanto física como funcionalmente. Esta agenda de modularización y estandarización abre perspectivas inmensas a la Biotecnología: los sistemas vivos se convierten en una fuente de materiales que permiten generar nuevos objetos y propiedades en poco o en nada parecidos a su función natural. Un promotor bacteriano que en su contexto nativo controla la expresión de un gen de resistencia a tetraciclina cuando las células se encuentran con el antibiótico en el medio se convierte por obra y arte de la Biología sintética en un módulo inversor (una puerta lógica NOT) que puede combinarse con otras para ejecutar cálculos y procesar señales que no son las suyas en origen (Silva-Rocha y de Lorenzo, 2008). Distintas enzimas bacterianas y vegetales pueden ensamblarse en una levadura para originar una ruta biosintética de una droga anti-malaria (Paddon y Keasling, 2014). Sitios de anclaje de proteínas derivados de rutas de señalización de metazoos se han utilizado para canalizar en Escherichia coli los substratos de una biotransformación de interés industrial (Dueber et al., 2009). Y así docenas de casos en los que una función biológica se descontextualiza con la herramientas del ADN recombinante (y más recientemente mediante síntesis química de secuencias de $A D N$ ) y se reutiliza en una situación distinta para hacer algo que la naturaleza no ha hecho o inventado antes.

\section{SIMPLIFICAR LA BIOLOGÍA PARA HACERLA MÁS FÁCIL DE (RE)DISEÑAR}

Este empeño tropieza con dos grandes retos. Por un lado, la composición física de las secuencias de ADN no se traduce necesariamente en una integración de las funciones correspondientes, al menos de forma cuantitativa. Y los parámetros asociados a las partes biológicas (por ejemplo, promotores, terminadores, sitios de unión de ribosoma, etc.) cambian a menudo con el contexto genómico y con las condiciones fisiológicas del hospedador. De hecho, el problema de la dependencia de contexto es una de las mayores limitaciones para diseñar dispositivos y biológicos fiables. Para remediar este estado de las cosas se han venido proponiendo varias líneas de acción.

Una de ellas es editar el genoma para eliminar la complejidad que no sea estrictamente necesaria para una cierta aplicación. En una primera fase, el genoma se puede limpiar de componentes que causan inestabilidad (por ejemplo, profagos, secuencias de inserción, elementos móviles, etc.), para continuar con bloques de genes que, aunque presentes y útiles en el medio natural, pueden no ser esenciales (por ejemplo, la maquinaria flagelar) en un bioreactor (Posfai et al., 2006). Luego puede venir la eliminación de bloques metabólicos no utilizados, estructuras del envoltorio celular y otros 
muchos genes que pueden considerarse innecesarios. Aunque con este abordaje uno podría minimizar el genoma y por tanto el contexto molecular de cualquier dispositivo que se pudiera implantar en él, lo cierto es que los intentos de reducir el genoma de bacterias modelo como $E$. coli no han conseguido ir más allá de un 20-30\% (Posfai et al., 2006). Aparte de la eliminación de posibles genes esenciales, quizá la deleción de grandes segmentos del cromosoma altere su arquitectura dentro de la célula y lo haga inviable. Una alternativa es ir en dirección exactamente contraria: partir de bacterias con genoma ya muy pequeños, por ejemplo Mycoplasma o endosimbiontes como Buchnera (van Ham et al., 2003). En estos casos, la propia naturaleza ha hecho el trabajo de reducción. Aunque en principio este puede ser un buen abordaje, el que un sistema tenga menos componentes no significa que la situación resultante sea más simple. La reducción de complejidad composicional se compensa con el incremento de la complejidad relacional: los cromosomas con menos genes originan células que son mucho más dependientes de sus interacciones con el entorno. Aun así, algunas bacterias con genomas pequeños (como Mycoplasma) son caballos de batalla de referencia en Biología sintética. Sobre todo porque el tamaño del cromosoma permite realizar su síntesis química completa, tal y como llevó a cabo el grupo de Venter (Gibson et al., 2010). Esto abre posibilidades de llevar a la práctica el escenario mencionado arriba de considerar a las bacterias y otros sistemas biológicos como ordenadores para los que se puede escribir un software (el DNA) que puede ser ejecutado por una maquinaria molecular ya existente. Las propuestas futuristas de Craig Venter sobre un futuro convertidor biológico digital (http://www.theguardian.com/science/2013/ oct/13/craig-ventner-mars) van exactamente en esta dirección.

\section{Ortogonalización}

Pero simplificar el genoma e incluso re-escribirlo por completo no soluciona todos los problemas. Como se mencionó antes, el funcionamiento, sobre todo cuantitativo de las partes biológicas está sujeto en mayor o menor medida a la influencia de varios niveles de contexto -desde interferencias con secuencias próximas hasta efectos globales y medioambientales. Para provecho de la evolución pero para irritación de los bio-ingenieros, los materiales biológicos (proteínas, polímeros, pequeñas moléculas, etc.) tienden a interactuar con sus vecinos moleculares de formas a menudo impredecibles. En Biología, $2+2$ no son siempre 4 porque cualquier nueva combinación está sujeta a la aparición de propiedades emergentes (negativas o positivas) que no pueden predecirse a partir de las cualidades de los componentes de la suma, al menos con el grado de conocimiento que tenemos en la mayoría de los casos. Una situación familiar a cualquier biotecnólogo es la incertidumbre sobre la eficiencia de sistemas de expresión heteróloga de genes de interés industrial. La combinación de un promotor fuerte con una señal de iniciación de la traducción también fuerte debería en principio conducir a una expresión (combinación transcripción+traducción) fuerte también del gen de interés. Esto sucede así en muchos casos, pero en otros acontece exactamente lo contrario. ¿Por qué? Muy frecuentemente, el extremo 5' del tránscrito forma estructuras secundarias inesperadas con secuencias más abajo del gen en cuestión, lo que genera una gran inestabilidad en el ARNm o impide la traducción.

Un posible remedio a estas situaciones es la asíllamada ortogonalización de los componentes que van en un sistema. Dos sistemas son mutuamente ortogonales si no se influencian el uno al otro. Es concebible partir de un componente o un módulo biológico muy conectado y producir una variante que conserve solo la conectividad deseada y así facilitar su uso en nuevos diseños biológicos. La propia naturaleza ofrece casos de partes ortogonales, típicamente en elementos móviles promiscuos y bacteriófagos (por ejemplo, la RNA polimerasa del fago T7). Pero también se han hecho grandes avances en desarrollar códigos genéticos alternativos y ribosomas ortogonales capaces de descifrarlos. Quizá en el futuro no muy lejano podamos disponer de entidades biológicas con un genoma que codifique la información con un cifrado genético distinto (incluso con bases nonaturales; Malyshev et al., 2014) que se exprese con polimerasas alternativas y produzca un mensaje que se traduzca por ribosomas ortogonales. De hecho, el objeto vivo resultante sería tan lejano a lo existente que no podría interaccionar de ninguna forma con los sistemas biológicos naturales, asegurando así su contención y la seguridad de su utilización biotecnológica (Schmidt y de Lorenzo, 2012).

\section{¿Frenar la evolución?}

Los desafíos que debe de enfrentar la Biología sintética para convertirse en una auténtica rama de la ingeniería no terminan con lo enunciado hasta ahora. 
De hecho aún queda el más importante: asegurarse que cualquier dispositivo objeto vivo diseñado por los bio-ingenieros mantiene sus propiedades a lo largo del tiempo y no sucumbe al ruido y las mutaciones -o desarrolle propiedades emergentes. Incluso si conseguimos un diseño optimizado de un circuito biológico o de un sistema completo, es inevitable que tras un tiempo el ADN que lo determina mute (mucho más si hay estrés ambiental) y eso lleve al colapso final de la entidad. La literatura científica y biotecnológica contiene numerosos ejemplos de microorganismos recombinantes diseñados para una cierta función que tras un tiempo, dejan de ejecutar el programa genético esperado debido a la acumulación de mutaciones. La pregunta obvia es si podemos forzar de forma estable a los sistemas naturales a hacer en nuestro propio beneficio algo que habitualmente no hacen. La estrategia predominante para abordar este gran reto es la de penalizar (también mediante circuitos genéticos ad hoc) las mutaciones que lleven a no conseguir los objetivos, por ejemplo induciendo el suicidio de los mutantes indeseados. Pero como cualquier construcción genética, los circuitos de letalidad condicional están sujetos a adquirir mutaciones que los hagan ineficientes. Es este un reto que está planteado pero en absoluto solucionado aún. Las propuestas pasan desde la permuta de las moléculas que portan la información (del ADN a polímeros parcial o totalmente artificiales) hasta el cambio total del soporte de la información, de ser encriptada por un código a estar determinada por una composición lipídica. Es este un cuello de botella real que deberá ser abordado para que la Biología sintética llegue a realizar todas sus promesas.

\section{LA BIOLOGÍA SINTÉTICA EN ESPAÑA}

Nuestro país no ha sido ajeno al desarrollo de la Biología sintética en la última década. Científicos como Luis Serrano (CRG, Barcelona) participaron muy activamente en la definición del campo dentro de la Unión Europea a través del informe NEST del año 2005 encargado por la CE a un grupo de alto nivel. Ese mismo año, el autor de este artículo organizó en el Castillo de Magalia (Ávila) el primer Workshop Europeo de Biología Sintética patrocinado por la Fundación Europea de la Ciencia. Poco después, equipos españoles comenzaron a intervenir en la competición internacional de diseños biológicos denominada iGEM (http://igem. org), uno de los mayores escaparates del campo en el que participan grupos de estudiantes pre-graduados de Biología e Ingeniería. En la actualidad hay grupos de Investigación que explícitamente se identifican como de Biología sintética en Madrid, Barcelona, Va- lencia, Lérida y Sevilla. Por otra parte, un número considerable de equipos de trabajo en Biología molecular y Biotecnología españoles en la Universidad y el CSIC realizan actividades que perfectamente cualifican como Biología sintética, a pesar de no hacerlo directamente bajo esa denominación. En la mayor parte de los casos, la gravitación hacia el campo en nuestro país viene de Biólogos que se mueven hacia la Ingeniería y no de Ingenieros que se interesan por la Biología. Esta tendencia, que se asemeja a la de otros países europeos, es diferente al desarrollo de la disciplina en USA, en donde la Biología sintética contemporánea está protagonizada mayoritariamente por ingenieros eléctricos y computacionales. Un excepción notable es la de la Universidad Politécnica de Valencia, que ha tenido un papel pionero en movilizar el interés de ingenieros españoles hacia la Biología sintética. De hecho, para el desarrollo de la temática en nuestro país sería altamente deseable que las Escuelas de Ingeniería incorporaran asignaturas de Biología molecular y Biología sintética como parte de su currículum central y que se crearan Departamentos de Investigación en Biología en el entorno técnico y cuantitativo de las Ingenierías tradicionales. Es esencial que los ingenieros y los biólogos trabajen juntos en vez de ser unos meros asistentes de los otros. No es esta una cultura aún predominante, pero por necesidad o virtud es necesario avanzar hacia ella.

Quizá el necesario maridaje entre las Ciencias de la Vida y la Ingeniería que está en la base de la Biología sintética sea más fácil de llevar a cabo en el ambiente dinámico de la empresa. Aunque son pocas aún las aventuras empresariales que se identifican a sí mismas dentro del campo en España, algunas grandes entidades como REPSOL o ABENGOA han incluido en sus Departamentos de I+D secciones en Biología sintética, sobre todo orientadas a los biocombustibles y las biotransformaciones. Otras empresas de origen tecnológico creadas desde Centros de Investigación públicos incorporan en su portfolio a la Biología sintética como una herramienta más para sus objetivos científicos e industriales. La más característica y activa de este tipo es Biopolis SL (http://www. biopolis-biotech.com), una empresa centrada en el sector agroalimentario que es de referencia para la biotecnología española. Pero lamentablemente, en el listado de entidades de pequeño y mediano tamaño que se agrupan en la Asociación de Empresas Españolas de Biotecnología (ASEBIO) no hay ninguna cuya actividad principal sea la Biología sintética. La única excepción por el momento es este panorama es Bacmine SL (www.bacmine.com), una PME fundada por 
científicos del Centro Nacional de Biotecnología del CSIC que se centra en el diseño de microorganismos para aplicaciones ambientales e industriales.

Si de la Química moderna que nació con Lavoisier surgió mucho más tarde la Ingeniería química, es posible que en un periodo de tiempo mucho más corto veamos la Biología sintética traducir en productos y servicios el enorme conocimiento en las Ciencias de la Vida que hemos acumulado hasta ahora. Nuestro país tiene aún la oportunidad de situarse en grupo de cabeza de este panorama internacional de la Biología sintética. Cuatro grupos de investigación españoles (de Lorenzo en el CSIC, Moya en la U. de Valencia, Serrano en el CRG Barcelona y Valencia en el CNIO) fueron listados en el año 2008 por la revista Science entre los equipos más prominentes internacionalmente en la disciplina (http://sciencecareers. sciencemag.org/career_magazine/previous_issues/ articles/2008_10_17/caredit.a0800151). Sin embargo, mientras que la CE y los USA han apostado decisivamente por ella como uno de los pilares de la Bioeconomía del futuro, este impulso no se ha traducido aún en un envite decidido en España por parte de las administraciones o las empresas. Mientras el campo se encuentre aún en un periodo fundacional en el que el talento sea más importante que el músculo, aún tendremos una buena oportunidad de situarnos en el paisaje futuro de esta disciplina. Pero esa ventana de oportunidad puede perderse muy rápidamente si las actividades y grupos ya existentes se descapitalizan por la crisis y no se genera una masa crítica suficiente en los próximos años.

\section{¿QUÉ HACER?}

La agenda investigadora de la Biología sintética puede fácilmente deducirse de lo dicho hasta ahora en este artículo. El mayor obstáculo para la ingeniería de sistemas biológicos es la influencia del contexto multiescala en el funcionamiento de los componentes individuales de cualquier entidad viva. La reducción de la complejidad genómica, la ortogonalización de las partes y dispositivos a combinar y la eliminación de mutantes que pierden el programa implantado en ellos son obviamente caminos a seguir. Pero eso no es todo. Hay preguntas biológicas fundamentales que debemos responder para poder avanzar por en el diseño de tales objetos. La primera es clarificar la relación entre metabolismo, crecimiento, división y proliferación células, empezando por lo más simple, las bacterias. Como se mencionó antes, a diferencia de los dispositivos hechos por el hombre, los sistemas vivos crecen y eso añade una complejidad extraordinaria a la hora de diseñarlos de forma predecible. En el mejor de los casos, uno quisiera disponer de células que ejecutan las funciones para las que han sido diseñadas pero sin crecer. Esto plantea retos de investigación fascinantes, porque cualquier programa implementado con componentes materiales envejece y comete errores. Y la forma que los sistemas biológicos tienen de repararlos es creándolos de nuevo en las copias que se generan durante el crecimiento. Dado que la agenda evolutiva de los seres vivos es el éxito reproductivo ¿podemos desacoplar ese crecimiento del resto de la funcionalidad biológica sin alterar seriamente a las células correspondientes? Aquí hay un problema que difícilmente puede contestar solo la Biología molecular, porque tiene derivadas en la teoría de la información, en la resistencia de nano-materiales y en la ingeniería de sistemas mecánicos.

Otra limitación aún por explorar en detalle es la influencia del metabolismo en el flujo de expresión génica. Las abstracciones de los circuitos y módulos a implantar en los sistemas biológicos a menudo ocultan que su acción se ejecuta en un medio químico complejo con una lógica propia y con una alta reactividad. Lo que en la jerga de la Biología sintética se denomina chasis se compone no solo de un genoma más o menos intrincado sino también de un escenario con una gran complejidad molecular que apenas conocemos. De cómo entendamos esa complejidad multi-escala y multi-molecular dependerá en gran medida el que los desarrollos en marcha de la Biología sintética se conviertan en tecnologías robustas o se queden en meras anécdotas.

En el mejor de los casos, una vez que se tienen a mano componentes fiables para la construcción de un objeto complejo (como un Meccano o un Lego) es cuestión de la imaginación del usuario el producir todo tipo de artículos y materiales, desde biocombustibles, biocatalizadores y nuevos agentes terapéuticos a formas de computación distintas, bioplásticos y fibras inteligentes o biosensores para moléculas de todo tipo. $Y$ es justamente en la imaginación y creatividad donde nuestra comunidad científica y técnica puede hacer las mayores contribuciones al campo y llegar a donde no ha podido llegar grandes iniciativas en Biología sintética en los EEUU basadas en el poderío técnico, como el Programa SynBERC (http://www.synberc.org). Para ello es necesario fomentar la interfase Ciencias de la Vida-Ingeniería en los programas académicos de las Universidades y promover titulaciones que integren a partes iguales Biología Fundamental y principios de Ingeniería. Por el momento, 
muchos biólogos moleculares alegan que los Ingenieros saben poco o nada de Biología y por tanto es difícil interaccionar con ellos. Y a su vez, los Ingenieros ven a buena parte de los Biólogos como carentes del talento cuantitativo y formación matemática que se necesita para el diseño de sistemas que realmente funcionen. La superación de esta barrera cultural es posiblemente el mayor reto al que nos enfrentamos en España, pero del que dependemos para no ser meros espectadores, sino más bien actores, del nuevo tipo de Bio-industria que veremos desarrollarse en las próximas décadas.

\section{AGRADECIMIENTOS}

El trabajo en el Laboratorio del Autor está financiado por la Unión Europea (Grants ARYSIS, ST-FLOW y EVOPROG), por el Programa BIO del Ministerio de Economía y competitividad y por el Proyecto PROMT de la Comunidad Autónoma de Madrid. VdL está agradecido a Antoine Danchin por su constante inspiración sobre los temas examinados en este artículo.

\section{BIBLIOGRAFÍA}

Acevedo-Rocha, C. G., Fang, G., Schmidt, M., Ussery, D. W. y Danchin, A. (2013). From essential to persistent genes: a functional approach to constructing synthetic life. Trends in Genetics, 29, pp. 273-279. http://dx.doi.org/10.1016/j. tig.2012.11.001

Barabasi, A. L. y Oltvai, Z. N. (2004). Network biology: understanding the cell's functional organization. Nature Reviews Genetics, 5, pp. 101-113. http://dx.doi. org/10.1038/nrg1272

Cases, I. y Lorenzo, V. de (2001). The black cat/white cat principle of signal integration in bacterial promoters. $E M B O$ Journal, 20, pp. 1-11. http://dx.doi. org/10.1093/emboj/20.1.1

Danchin, A. (2009a). Bacteria as computers making computers. FEMS Microbiology Reviews, 33, pp. 3-26. http://dx.doi. org/10.1111/j.1574-6976.2008.00137.x

Danchin, A. (2009b). Information of the chassis and information of the program in synthetic cells. Systems and Synthetic Biology, 3, pp. 125-134. http://dx.doi. org/10.1007/s11693-009-9036-5

Dueber, J. E., Wu, G. C., Malmirchegini, G. R., Moon, T. S., Petzold, C. J., Ullal, A. V., Prather, K. L. y Keasling, J. D. (2009). Synthetic protein scaffolds provide modular control over metabolic flux. $\mathrm{Na}$ ture Biotechnology, 27, pp. 753-759. http://dx.doi.org/10.1038/nbt.1557

Endy, D. (2005). Foundations for engineering biology. Nature, 438, pp. 449453. http://dx.doi.org/10.1038/nature04342
Gibson, D. G., Glass, J. I., Lartigue, C., Noskov, V. N., Chuang, R.-Y., Algire, M. A., Benders, G. A., Montague, M. G., Ma, L. y Moodie, M. M. (2010). Creation of a bacterial cell controlled by a chemically synthesized genome. Science, 329, pp. 52-56. http://dx.doi.org/10.1126/science.1190719

Ham, R. C. H. J. van, Kamerbeek, J., Palacios, C., Rausell, C., Abascal, F., Bastolla, U., Fernández, J. M., Jiménez, L., Postigo, M., Silva, F. J., Tamames, J., Viguera, E., Latorre, A., Valencia, A., Morán, F. y Moya, A. (2003). Reductive genome evolution in Buchnera aphidicola. Proceedings of the National Academy of Sciences of the United States of America, 100, pp. 581-586. http://dx.doi. org/10.1073/pnas.0235981100

Huerta, S. (2006). Structural design in the work of Gaudi. Architechtural Science Review, 49, pp. 324-339. http://dx.doi. org/10.3763/asre.2006.4943

Jacob, F. (1977). Evolution and tinkering. Science, 196, pp. 1161-1166. http:// dx.doi.org/10.1126/science.860134

Kosuri, S., Goodman, D. B., Cambray, G., Mutalik, V. K., Gao, Y., Arkin, A. P., Endy, D. y Church, G. M. (2013). Composability of regulatory sequences controlling transcription y translation in Escherichia coli. Proceedings ofthe National Academy of Sciences of United States of America, 110, pp. 14024-14029. http:// dx.doi.org/10.1073/pnas.1301301110

Lorenzo, V. de (2014). From the selfish gene to selfish metabolism: Revisiting the central dogma. Bioessays, 36, pp. 226-235. http://dx.doi.org/10.1002/ bies. 201300153

Lorenzo, V. de y Danchin, A. (2008). Synthetic biology, discovering new worlds and new words. EMBO Reports, 9, pp. 822-827. http://dx.doi.org/10.1038/ embor.2008.159

Malyshev, D. A., Dhami, K., Lavergne, T., Chen, T., Dai, N., Foster, J. M., Corrêa, I. R. y Romesberg, F. E. (2014). A semisynthetic organism with an expanded genetic alphabet. Nature, 509, pp. 385388. http://dx.doi.org/10.1038/nature13314

Milanesio, P., Arce-Rodríguez, A., Muñoz, A., Calles, B. y Lorenzo, V. de (2011). Regulatory exaptation of the catabolite repression protein (Crp)-cAMP system in Pseudomonas putida. Environmental Microbiology, 13, pp. 324339. http://dx.doi.org/10.1111/j.14622920.2010.02331.x

Monod, J. (1970). Le hasard et la nécessité. Essai sur la philosophie naturelle de la biologie moderne. Paris: Editions du Seuil.

Mutalik, V. K., Guimaraes, J. C., Cambray, G., Mai, Q. A., Christoffersen, M. J., Martin, L., Yu, A., Lam, C., Rodriguez, C., Bennett, G., Keasling, J. D., Endy, D. y Arkin, A. P. (2013). Quantitative estimation of activity and quality for collections of functional genetic elements. Nature Methods, 10, pp. 347-353. http:// dx.doi.org/10.1038/nmeth.2403 
Paddon, C. J. y Keasling, J. D. (2014). Semisynthetic artemisinin, a model for the use of synthetic biology in pharmaceutical development. Nature Reviews Microbiology, 12, pp. 355-367. http:// dx.doi.org/10.1038/nrmicro3240

Porcar, M., Latorre, A. y Moya, A. (2013). What symbionts teach us about modularity. Frontiers in Bioengineering and Biotechnology, 1. http://dx.doi. org/10.3389/fbioe.2013.00014

Posfai, G., Plunkett, G. 3rd, Feher, T., Frisch, D., Keil, G. M., Umenhoffer, K., Kolisnychenko,
V., Stahl, B., Sharma, S. S., de Arruda, M., Burland, V., Harcum, S. W. y Blattner, F. R. (2006). Emergent properties of reduced-genome Escherichia coli. Science, 312, pp. 1044-1046. http://dx.doi.org/10.1126/science.1126439

Schmidt, M. y Lorenzo, V. de (2012). Synthetic constructs in/for the environment, managing the interplay between natural y engineered Biology. FEBS Let ters, 586, pp. 2199-2206. http://dx.doi. org/10.1016/j.febslet.2012.02.022

Schrödinger, E. (1944). What is Life? Cambridge: Cambridge University Press.
Silva-Rocha, R. y Lorenzo, V. de (2008). Mining logic gates in prokaryotic transcriptional regulation networks. FEBS Letters, 582, pp. 1237-1244. http://dx.doi. org/10.1016/j.febslet.2008.01.060

Watson, J. D. (1968). The Double helix. A personal account of the discovery of the structure of DNA. New York: Atheneum. 